\title{
Twins dispute memory ownership: A new false memory phenomenon
}

\author{
MERCEDES SHEEN and SIMON KEMP \\ University of Canterbury, Christchurch, New Zealand \\ and \\ DAVID RUBIN \\ Duke University, Durham, North Carolina
}

\begin{abstract}
In three experiments, we examined a new memory phenomenon: disputed memories, in which people dispute ownership of a memory. For example, in one disputed memory each of two twins recollected being sent home from school for wearing too short a skirt, although only one of them was actually sent home. In Experiment 1, 20 sets of same-sex adult twins were asked to produce a memory for each of 45 words, and most twins spontaneously produced at least one disputed memory. In Experiment 2, 20 different sets of same-sex adult twins rated disputed memories as higher in recollective experience, imagery, and emotional reliving than nondisputed memories. In Experiment 3, siblings who were close in age as well as same-sex friends were also found to have disputed memories, but less often than twins.
\end{abstract}

Our autobiographical memories define who we are and tie us to our personal histories. Imagine, then, what it is like when someone else claims your personal memories as their own. Personal and anecdotal evidence suggest that the ownership of memories is occasionally disputed by twins, and our aim in the present paper was to investigate this phenomenon.

Twins have long been used as participants in psychological research, mainly in the realm of behavior genetics and trait personality (Carver \& Scheier, 2000). We focused on using twins as participants as a starting point in the experiment of disputed memories because (1) we have observed disputed memories anecdotally in twins; (2) twins often look similar to each other, allowing for perceptual confusion in imagery within the twins; (3) twins look similar to each other, allowing for perceptual confusions in others who might innocently implant a false memory; (4) twins are siblings of the same age and thus share an unusually large proportion of their histories, and hence they have more chance to generate disputed memories; and (5) twins, particularly monozygotic twins, tend to assimilate their personalities (Plomin, DeFries, \& McClearn, 1990).

Our aim in this early stage of the research was not to ascertain the accuracy of the memories, nor to resolve questions of who owned them. Instead we focused on

We are grateful for suggestions from Christopher Burt, Mark Wheeler, and two anonymous reviewers. We thank Janine Buckner, Jennifer Peluso, and Jennifer Zervakis for their insights into autobiographical memory in twins. Address correspondence to S. Kemp, Psychology Department, University of Canterbury, Christchurch, New Zealand (e-mail: s.kemp@ psyc.canterbury.ac.nz). such questions as the following: Do twins have disputed memories, and if so, how often? Are monozygotic twins more likely to report disputed memories than dizygotic twins? What kinds of memories are disputed? Are these disputed memories similar between twins? Do they differ from ordinary, nondisputed memories? Is the possession of disputed memories limited to twins?

The present research can be seen as an example of the increasing interest that researchers have shown in the last 15 years in the fallible nature of autobiographical memory. Much emphasis has been placed on the reconstructive processes involved in recollecting personal memories and on the cognitive processes involved in making autobiographical memory errors (Hyman, 1999). Studies that have focused on memory errors include research on source monitoring failures (Johnson, 1988; Johnson \& Raye, 1981; Pope, 1996), the creation of false memories (Hyman \& Billings, 1998), the misinformation effect (Loftus, 1979, 1992; Zaragoza \& McCloskey, 1989), loss and distortion of memory content (Bahrick, 1979), and unconscious plagiarism (Bink, Marsh, Hicks, \& Howard, 1999).

Disputed memories differ from memory errors studied by other researchers in that the major detail that is in dispute is who the protagonist in the event is, a detail that is at the heart of the definition and use of self in autobiographical memory. From the existing literature on autobiographical memory, several factors emerge as being of possible importance for our understanding of this phenomenon. For example, people frequently cite reports of visual imagery to support the authenticity of their autobiographical memories. They argue that because they can "see it as plain as day" or "as if it were happening 
right now," they must be correctly remembering a past event (Rubin, 1998). In fact, false reports of visual imagery have been almost trivially easy to induce in laboratory settings (Hyman \& Pentland, 1996; Roediger, McDermott, \& Goff, 1997). Research has also shown that participants report visual imagery when the image is either inferred (Loftus \& Hoffman, 1989) or schema-based (Brewer \& Pani, 1983; Brewer \& Treyens, 1981). Hence, in our second experiment we paid attention to the imagery that was reported as present in the disputed memories.

One aspect of an image is whether the experience is recalled from the individual's own field of view or from the standpoint of a third-party observer. Nigro and Neisser (1983) demonstrated that the point of view taken during recollection was related to the purpose of recall, the characteristics of the original experience, and the time elapsed between event and recall. They proposed that memories recalled from the observer's perspective must, by their very nature, be reconstructed, because the original event must have been experienced from the field perspective. Their results suggested that older or less emotional memories are recalled from the observer's perspective and that more recent or highly emotional memories are recalled from the field perspective. The participants in our second experiment were asked to report on whether they recalled their memories through their own eyes or through the eyes of an observer.

An important methodological issue concerns how disputed memories should be elicited. Clearly, there would be much less risk of demand characteristics influencing the results if twins produced memories in response to Galton's method of semantic cuing (Crovitz \& Shiffman, 1974; Galton, 1880; Rubin, 1982) without mention of disputed memories. This method, however, has disadvantages: It is not possible for the cue words to cover every situation that might give rise to a disputed memory. The cue word method does, however, allow for a base-line measure of the frequency and types of memories that are disputed. There is also some advantage in applying a traditional autobiographical memory research tool to a new area of research.

An alternative way of eliciting disputed memories is simply to ask people whether or not they have experienced disputed memories with others and then to collect data on those memories. This method acts as a good catchall for collecting data on disputed memories, but there is, of course, the risk that demand characteristics might encourage participants to report a higher number of disputed memories than they have in fact actually experienced.

The last matter that needed to be considered was whether or not the occurrence of disputed memories is exclusive to twins. Do other sets of the population, such as siblings, also experience this kind of memory error?

In view of these methodological concerns, we conducted three experiments on this memory phenomenon. In the first experiment reported here, we used the cue word method of eliciting autobiographical memories. This experiment was carried out to determine whether disputed memories could be uncovered without participants' being specifically prompted for them. The second experiment involved asking twins directly whether they had experienced disputed memories with their co-twins, and these memories were compared with their shared nondisputed memories (i.e., shared autobiographical memories on whose ownership both agreed) using a questionnaire devised by Rubin, Schrauf, and Greenberg (1999). This questionnaire focuses on different properties and component processes of mental experience that are central to autobiographical memory, such as visual imagery and belief in one's memory, and it asks participants to report on the phenomenal characteristics of their autobiographical memories.

The scales in the questionnaire are intended to measure many properties of autobiographical memory; several were suggested by theories of autobiographical memory. For example, we attempted to assess the importance of belief in one's memory (Ross, Buehler, \& Karr, 1998) by having participants respond on a sevenpoint scale to the question "I believe the event in my memory really occurred in the way I remember it and that I have not imagined or fabricated anything that did not occur." Other scales represent theoretical elements such as rehearsal-particularly spaced rehearsal, which Bahrick (1979) suggested greatly improved retention levels-episodic/semantic memory (Tulving, 1972), auditory and visual imagery (Reisberg, 1992), reliving of emotions (Christianson, 1996), and significance of the memory (Pillemer, 1998).

In the third experiment, we administered a brief questionnaire to non-twins to see whether they too would report having experienced disputed memories.

\section{EXPERIMENT 1}

\section{Method}

Twenty sets of same-sex twins, (16 female) were recruited through advertisements in the local media and by posters around the university. They had a mean age of 27 years and a median age of 20 (range, 16-56). Eleven sets were monozygotic twins, and 9 sets were dizygotic. Upon initial contact, the twins were told that the experiment was about personal memory in twins and that they would be asked to provide autobiographical memories in response to the presentation of common words. They were then asked to contact their co-twins to arrange a convenient time when both of them could be interviewed together. The interviews took place in one of the twins' homes. After a few moments' introduction, permission to audio record the interview was obtained and recording commenced. The participants were briefly interviewed about their lives as twins and were asked whether they were monozygotic or dizygotic twins. Two sets of twins reported that their zygosity had never been determined, but that they had been raised to believe they were identical twins, and, given their similarity in appearance, they were recorded as monozygotic twins. After this brief informal interview, the participants were again told that the experiment was on autobiographical memory in twins, and they were instructed to come up with a specific autobiographical memory of a late childhood or early adolescent event (from the ages of 8-12) that they had experienced. The twins were asked to take turns providing the first memory for each cue word. The 45 cue words, selected to cue common events, were presented randomly, and whenever the partic- 
ipants provided a general memory in response to presentation of a cue word they were prompted by the interviewer for an eventspecific memory. These sessions typically took $1-2 \mathrm{~h}$.

\section{Results}

The 20 sets of twins reported 36 disputed memories in total; 14 had disputed memories with their twin and 6 had no disputed memories. The mean number of disputed memories reported was 1.8 (range, $0-14$ ), and the age of the twins at the time at which the event had occurred varied from 5 to 14 , with a median age of 8 years.
Chi-square analysis performed on both gender and zygosity showed no significant differences in the number of disputed memories that the twins reported. Brief descriptions of the disputed memories reported by fourteen sets of twins are shown in Table 1.

One of the interesting results of Experiment 1 was how many new disputed memories were discovered through the context of the experiment. Of the 36 disputed memories, 21 were discovered as disputed in the context of the experiment, and 15 were known to have been disputed prior to the experiment. Table 2 shows the distribution of new

Table 1

Description of Disputed Memories for Cue Word Experiment

\begin{tabular}{|c|c|c|c|c|}
\hline $\begin{array}{l}\text { Participant } \\
\text { and Zygosity }\end{array}$ & $\begin{array}{l}\text { Age } \\
\text { Now }\end{array}$ & $\begin{array}{c}\text { Age at } \\
\text { Disputed } \\
\text { Memory }\end{array}$ & Cue Word & Description of Memory \\
\hline $\mathrm{A} \mathrm{mz}$ & 21 & 5 & Bicycle & Both believe they were pushed off their bike by their cousins \\
\hline A mz & 21 & 6 & Bicycle & Both had a recurring dream of Singapore during war \\
\hline $\mathrm{A} \mathrm{mz}$ & 21 & 5 & Swing & Both think they swung across a pond on a vine and fell in pond \\
\hline A mz & 21 & 6 & Accident & Both think they got a nail in their foot \\
\hline $\mathrm{A} \mathrm{mz}$ & 21 & 11 & Barbecue & Both think they were asked to do a display dive at school \\
\hline A mz & 21 & 5 & Accident & Both think the other was chased by a swarm of wasps \\
\hline A mz & 21 & 8 & Christmas & Disagree about who discovered Xmas presents in parents' closet \\
\hline A mz & 21 & 11 & Fair & Both think they came 12 th in an international cross country race \\
\hline A mz & 21 & 7 & Church & Argue over who disobeyed superstition and pointed at the moon \\
\hline A mz & 21 & 12 & Clothing & Both think the other wore a terrible outfit and was caught by a boy \\
\hline A mz & 21 & 6 & Grandparents & $\begin{array}{l}\text { Argue over who got caned by their grandmother for something the other } \\
\text { twin did }\end{array}$ \\
\hline A mz & 21 & 14 & Restaurant & Who went for lunch with their mum and had a worm in her meal \\
\hline A mz & 21 & 5 & Fireworks & Rabbit lantern catching on fire during Chinese Festival \\
\hline A mz & 21 & 12 & Boat & Argue over who was in boat with their father when they saw a tiger shark \\
\hline $\mathrm{B} \mathrm{mz}$ & 54 & 7 & Picnic & Disagree about who threw a sandwich away on a picnic \\
\hline $\mathrm{B} \mathrm{mz}$ & 54 & 9 & Picnic & $\begin{array}{l}\text { Disagree about which one of them used to habitually squish pound cake } \\
\text { in their hands }\end{array}$ \\
\hline $\mathrm{Edz}$ & 16 & 8 & Trouble & One of them got into severe trouble for something the other did \\
\hline $\mathrm{Fdz}$ & 20 & 8 & Accident & Argue over who got a nail in their foot \\
\hline $\mathrm{Fdz}$ & 20 & 8 & Accident & Both say the other ate half the contents of a mustard jar and was sick \\
\hline $\mathrm{Fdz}$ & 20 & 5 & Birthday & Both think they got their ear glued to their head by a birthday party guest \\
\hline $\mathrm{H} \mathrm{dz}$ & 17 & 13 & Holiday & Disagree over who befriended a girl while they were on holiday \\
\hline I mzm & 19 & 12 & Sport & $\begin{array}{l}\text { Both think it was their name that their rugby coach got wrong } \\
\text { during an important match }\end{array}$ \\
\hline $\mathrm{J} \mathrm{mz}$ & 17 & 5 & Pet & Both think the other twin used to grab their dog by its testicles \\
\hline $\mathrm{K} \mathrm{mz}$ & 17 & 9 & Car & Argue over who, on a trip in a car, threw up over everyone \\
\hline $\mathrm{K} \mathrm{mz}$ & 17 & 5 & $\begin{array}{l}\text { 1st day } \\
\text { at school }\end{array}$ & Argue over what each other wore during their first day at school \\
\hline $\mathrm{Ldz}$ & 21 & 7 & Sport & Argue over who played goal attack during a game of kiwi netball \\
\hline $\mathrm{Mdz}$ & 19 & 6 & Birthday & Disagree about who got a particular present that they both loved \\
\hline $\mathrm{Mdz}$ & 19 & 10 & Car & Disagree as to who was in the back seat of car during accident \\
\hline Nmzm & 16 & 9 & Fair & Disagree about who went on a roller coaster at a fairground \\
\hline $\mathrm{P} \mathrm{mz}$ & 54 & 8 & Accident & Disagree about who fell over when a wheel came off rollerskate \\
\hline $\mathrm{Pmz}$ & 54 & 10 & Birthday & Both think they were the one not invited to a friend's birthday party \\
\hline $\mathrm{Pmz}$ & 54 & 7 & Birthday & Disagree about whose head got dunked when bobbing for apples \\
\hline $\mathrm{P} \mathrm{mz}$ & 54 & 8 & Trouble & Both say the other was the one who stole lollies from a shop \\
\hline $\mathrm{R} \mathrm{dz}$ & 29 & 9 & Trouble & Argue over who got into a fight in the playground at school \\
\hline S mzm & 56 & 13 & Doctor & Both think they fell off a tractor and sprained their wrist \\
\hline S mzm & 56 & 8 & Church & Both think the other got in trouble for throwing things in Church \\
\hline
\end{tabular}

Note-mz, monozygote; $\mathrm{dz}$, dizygote; $\mathrm{m}$, male. 
Table 2

Number of New and Old Disputed Memories

\begin{tabular}{lcccccc}
\hline $\begin{array}{c}\text { Number of } \\
\text { Disputed } \\
\text { Memories }\end{array}$ & $\begin{array}{c}\text { No. of } \\
\text { twins }\end{array}$ & $\begin{array}{c}\text { Old } \\
\text { Dispute }\end{array}$ & $\begin{array}{c}\text { New } \\
\text { Dispute }\end{array}$ & Positive & Neutral & Negative \\
\hline 0 & 6 & - & - & - & - & - \\
1 & 7 & 4 & 3 & 2 & 3 & 2 \\
2 & 4 & 3 & 5 & - & 3 & 5 \\
3 & 1 & 2 & 1 & - & 1 & 2 \\
4 & 1 & 2 & 2 & - & - & 4 \\
14 & 1 & 4 & 10 & 2 & 3 & 9 \\
Totals & 20 & 15 & 21 & 4 & 10 & 22 \\
\hline
\end{tabular}

and old disputed memories together with a rating of whether the disputed memory was for a negative, positive, or neutral event.

Disputed memories were reported for 21 of the 45 cue words. The cue word accident produced five disputed memories; birthday produced four disputed memories; being in trouble elicited three disputed memories; fairground, church, picnic, sport, bicycle, and car elicited two disputed memories; and swings, barbecue, Christmas, clothing, grandparents, restaurant, fireworks, boat, holiday, pet, first day at school, and doctor each produced one disputed memory.

\section{EXPERIMENT 2}

\section{Method}

Forty people responded to newspaper advertisements for samesex twins to take part in an experiment on autobiographical memory. (The advertisement did not mention disputed memories, and none of the people from Experiment 1 took part in Experiment 2.) Thirtyone of these respondents were women, and 9 were men. The respondents were given the example of the disputed memory described in the abstract, in which both twins dispute who was sent home from school for wearing too short a skirt. The respondents were then asked whether they had experienced a disputed memory. Of the original 40, 25 females and 1 male reported that they disputed at least one memory with their twin. A test of proportion showed no significant (at the $p<.05$ level) difference between the $65 \%$ of twins who responded positively on this question and the $70 \%$ of twins in Experiment 1 who came up with at least one disputed memory during the cue word procedure. Chi-square analysis showed that female twins were significantly more likely to report having had disputed memories than male twins $\left[\chi^{2}(1)=7.95, p<.01\right]$.

Owing to difficulties in availability (it was not always possible to interview both of the twins), only 19 sets of female and 1 set of male twins took part in the subsequent experiment. The participants were asked to contact their twins to discuss the research and in particular to think of as many memories as possible for which they believed ownership was disputed. Ten sets of twins were monozygotic (identical) and 10 dizygotic (fraternal). Their ages at the time of the experiment ranged from 17 to 52 years, with a median age of 24 .

Meetings took place at one of the twins' houses or in a meeting room at the university. The first author asked the twins to provide 10 autobiographical memories in total-up to 5 disputed memories, with the remainder memories that were shared but whose ownership was not in dispute. For example, if the twin pair had 2 disputed memories, they were then asked to provide 8 nondisputed memories. For a memory to be included, both twins had to confirm that they had a clear recollection of the event. The twins were then asked to come up with a one-sentence description of each memory, beginning with the disputed memories. The researcher recorded the one-sentence descriptions on the top of a separate questionnaire for each twin.

Once this was complete, each twin was given the 10 autobiographical memory questionnaires and was asked to complete them. They did this individually in isolation. They were asked to consider each memory one at a time and to complete the disputed memory questionnaires first. The whole process typically took an hour, after which the twins were thanked for their time and were asked to contact the researcher if they recalled any further disputed memories.

The autobiographical memory questionnaires were adapted from those devised and used by Rubin et al. (1999). Each questionnaire contained 15 statements about the memory that were to be responded to on a 7-point scale (see the Appendix). In addition, the respondents were asked how old they were at the time of the event, and whether when they recalled the event, they imagined it through their own eyes (field) or from the perspective of an observer.

For the disputed memories only, the twins were also asked six additional questions: Who was present during the event, what they were doing at the time, how did they come to be there, how old they were when the event took place, and what they were doing immediately before and after the event?

\section{Results}

In total, the twins produced 33 disputed memories. Eight sets of twins reported having 1 disputed memory, 11 sets reported 2 disputed memories, and 1 set reported 3 disputed memories. Brief descriptions of disputed memories recalled by each of the pairs of twins are shown in Table 3. A chi-square test $\left[\chi^{2}(1)=0.3\right.$, n.s. $]$ indicated that zygosity did not affect the number of disputed memories that the twins reported. The age of the twins when the events occurred varied from 5 to 22 , with a median age of 10 years. Thus the incidents were recalled mainly from late childhood or adolescence. At one extreme, one set disputed a memory for an event that occurred 6 months previously; another set disputed the memory for an event that had occurred 46 years before.

An attempt to code the disputed memories failed to reveal any consistent themes in the events. The twins generally agreed on most of the details surrounding the event. Forty-five percent (15 out of 33) of the disputed memories were for events that occurred at home, and $51 \%$ (17 out of 33 ) involved people other than the twins.

In total, the twins reported 167 nondisputed memories. The mean age of the twins' disputed memories was 12.5 , and the mean age of their nondisputed memories was 11.9. Seventy-four percent of the disputed memories and 64 per cent of the nondisputed memories were recalled from the field perspective, and a test of proportion showed no significant difference between them (at the $p<.05$ level). Of the 33 disputed memories, 16 were recalled by both twins from their own field of view, 10 were recalled by one twin from the field and the other from an observer's point of view, and 7 were recalled by one twin from the field view while the other could not tell.

Table 4 shows the means of the ratings assigned to the disputed and nondisputed memories by the twins. The table shows systematic differences between the types of memory. As we noted earlier, many researchers have defined imagery as a central component of recollection (Brewer, 1986, 1996; Rubin, 1996, 1998; Tulving, 1983, 
1985; Wheeler, Stuss, \& Tulving, 1997). In this context, it is important to note that the disputed memories were rated higher on many of the scales intended to assess either recollection (e.g., reliving, and remember vs. know) and some aspect of sensory imagery (e.g., hearing, seeing, setting, and spatial layout). These memories were also rated as having a significantly greater real component and as producing more of the emotion originally felt. In brief, although the memories must have been partially fabricated for at least half of the sample, the measures of memory quality provide no indication of this.

All but one of the scales measuring recollection, imagery, and emotional reliving were significantly higher for the disputed memories, and none of the other scales were. The differences in recollection and in imagery and emotional reliving cannot have been due to differences in perceived significance of the event, reported rehearsal, language in the memory, or narrative coherence. Of special note is the observation that the disputed memories were no less believed than the nondisputed memories even though both twins realized that one of them was wrong. These observations are consistent with the realitymonitoring literature in which increased imagery leads to greater belief in a memory (Johnson \& Raye, 1981), but they offer little encouragement to those who would use detailed imagery to separate "true" from "false" memories. It could be argued that the higher ratings for disputed memories were merely a reflection of the twins' attempts to convince themselves (or the interviewer) that the memory was indeed theirs. It could further be argued that the methodology was partly to blame for the higher ratings for disputed memories. It seems unlikely, how-

Table 3

Disputed Memories for Each Pair of Twins: Experiment 2

\begin{tabular}{|c|c|c|c|c|c|}
\hline $\begin{array}{l}\text { Twin } \\
\text { Pair }\end{array}$ & $\begin{array}{l}\text { Age } \\
\text { Now }\end{array}$ & $\begin{array}{l}\text { Age at } \\
\text { Memory }\end{array}$ & Sex & Zygosity & Description of Memory \\
\hline $\mathrm{F}$ & 17 & 10 & $\mathrm{~F}$ & $\mathrm{Mz}$ & We both think we were the one who was sick and missed a week of school \\
\hline \multirow[t]{2}{*}{$\mathrm{P}$} & 18 & 9 & $\mathrm{~F}$ & $\mathrm{Mz}$ & We argue over who won the spelling prize at school, I say it was me \\
\hline & & 18 & $\mathrm{~F}$ & $\mathrm{Mz}$ & At Nana's funeral I sat with mum and she sat in the pew behind with dad \\
\hline \multirow[t]{2}{*}{$\mathrm{C}$} & 19 & 11 & $\mathrm{~F}$ & $\mathrm{Mz}$ & I was sleepwalking and walked into the dining room while dad was having breakfast \\
\hline & & 19 & $\mathrm{~F}$ & $\mathrm{Mz}$ & It was me who got my drivers license on my 19 th birthday \\
\hline \multirow[t]{2}{*}{ A } & 21 & 7.5 & $\mathrm{~F}$ & $\mathrm{Mz}$ & One of us forgot to give dad a very important phone message \\
\hline & & 5.5 & $\mathrm{~F}$ & $\mathrm{Mz}$ & $\begin{array}{l}\text { We were told not to touch an envelope on the dining table but one of us sealed it and got } \\
\text { into trouble from dad }\end{array}$ \\
\hline \multirow[t]{2}{*}{$\mathrm{T}$} & 22 & 8 & $\mathrm{~F}$ & $\mathrm{Mz}$ & She peeked at our Christmas presents and told me what they were \\
\hline & & 10 & $\mathrm{~F}$ & $\mathrm{Mz}$ & We were both in the same class but I felt sick and had to leave and threw up in the hallway \\
\hline \multirow[t]{2}{*}{$\mathrm{D}$} & 23 & 5 & $\mathrm{~F}$ & $\mathrm{Mz}$ & We were playing with building blocks and my brother $\mathrm{x}$ came over and knocked them over \\
\hline & & 8 & $\mathrm{~F}$ & $\mathrm{Dz}$ & I (not my sister) ran into a clothesline and cut my head \\
\hline $\mathrm{J}$ & 23 & 12 & $\mathrm{~F}$ & $\mathrm{Dz}$ & I got smacked by a very strange girl who thought I was my twin sister \\
\hline $\mathrm{K}$ & 23 & 10 & $\mathrm{~F}$ & $\mathrm{Dz}$ & We both think we were the one who had to have a wart removed \\
\hline \multirow[t]{2}{*}{$\mathrm{E}$} & 24 & 14 & $\mathrm{~F}$ & $\mathrm{Dz}$ & I went alone with my mother to pick up $\mathrm{x}$ \\
\hline & & 22 & $\mathrm{~F}$ & $\mathrm{Dz}$ & It was my meal that was awful and had to be sent back to the kitchen \\
\hline \multirow[t]{2}{*}{ I } & 24 & 9 & $\mathrm{~F}$ & $\mathrm{Dz}$ & We argue over who won a freestyle swimming race in a competition \\
\hline & & 15 & $\mathrm{~F}$ & $\mathrm{Dz}$ & $\begin{array}{l}\text { We were getting a drink from the fridge and she knocked over a jug of orange juice that } \\
\text { went all over the carpet }\end{array}$ \\
\hline \multirow[t]{2}{*}{$\mathrm{L}$} & 24 & 8 & $\mathrm{~F}$ & $\mathrm{Dz}$ & I got a hot water bottle with rabbits' ears on it for our birthday, hers didn't have rabbits' ears \\
\hline & & 14 & $\mathrm{~F}$ & $\mathrm{Dz}$ & I caught a fish when we went on holiday in $\mathrm{x}$, she says she caught it \\
\hline S & 25 & 10 & $\mathrm{~F}$ & $\mathrm{Mz}$ & We were skiing together and I broke my ski and had to walk down \\
\hline \multirow[t]{2}{*}{ G } & 26 & 8 & M & $\mathrm{Dz}$ & We were playing on our bikes when our neighbour pushed me off my bike \\
\hline & & 17 & M & $\mathrm{Dz}$ & He thinks he made a try-saving tackle in final but it was me \\
\hline $\mathrm{O}$ & 26 & 12 & $\mathrm{~F}$ & $\mathrm{Dz}$ & I had really bad chicken pox when I was young, she had it mildly \\
\hline Q & 28 & 11 & $\mathrm{~F}$ & $\mathrm{Dz}$ & I stayed alone in the tent after she went inside because she was cold \\
\hline $\mathrm{N}$ & 32 & 15 & $\mathrm{~F}$ & $\mathrm{Mz}$ & We both say that we danced with $\mathrm{x}$ all night at the school dance \\
\hline \multirow[t]{3}{*}{$\mathrm{H}$} & 42 & 6 & $\mathrm{~F}$ & $\mathrm{Mz}$ & She thinks it was her but it was me who got the dolls' house as a gift \\
\hline & & 12 & $\mathrm{~F}$ & $\mathrm{Mz}$ & I was the only one who played in the school marching band \\
\hline & & 12 & $\mathrm{~F}$ & $\mathrm{Mz}$ & Mum and dad didn't know, but I (not her) was on the stairs watching a movie \\
\hline \multirow[t]{2}{*}{ M } & 42 & 14 & $\mathrm{~F}$ & $\mathrm{Mz}$ & I lost my sister's earring, I remember feeling my ear and it was gone \\
\hline & & 7 & $\mathrm{~F}$ & $\mathrm{Mz}$ & We were in a dairy and I stole sweets from the shop and the man told our parents \\
\hline \multirow[t]{2}{*}{$\mathrm{R}$} & 46 & 6 & $\mathrm{~F}$ & $\mathrm{Dz}$ & We disagree about who knocked over a huge plant and got in trouble \\
\hline & & 6 & $\mathrm{~F}$ & $\mathrm{Dz}$ & $\begin{array}{l}\text { We always wore different colour clothing and it was me who had the yellow raincoat, } \\
\text { she had the blue one }\end{array}$ \\
\hline $\mathrm{B}$ & 52 & 5.5 & $\mathrm{~F}$ & $\mathrm{Mz}$ & She ran away from home, mum and I searched frantically for her \\
\hline
\end{tabular}

Note-For Age at Memory, when the twins disagreed about their ages, means were used. Twins were tested in the order of the lettering. Mz, monozygote; Dz, dizygote. 
Table 4

Mean Disputed and Nondisputed Memory Ratings

\begin{tabular}{|c|c|c|c|}
\hline Scale & Disputed & Nondisputed & $t$ value \\
\hline \multicolumn{4}{|c|}{ Recollection } \\
\hline Reliving & 5.5 & 4.7 & $4.31 * * *$ \\
\hline Actually remember the event & 6.1 & 5.7 & $2.62 *$ \\
\hline I travel back to the time & 5.0 & 4.8 & .82 \\
\hline \multicolumn{4}{|c|}{ Imagery and Emotion } \\
\hline Hear in my mind & 4.8 & 4.3 & $2.12 *$ \\
\hline See in my mind & 6.0 & 5.3 & $4.81 * * *$ \\
\hline Recall the setting & 6.1 & 5.7 & $2.52 *$ \\
\hline I know its spatial layout & 5.1 & 4.6 & $2.66^{*}$ \\
\hline Feeling the emotion now & 5.4 & 4.8 & $2.41 *$ \\
\hline \multicolumn{4}{|c|}{ Language and Narrative } \\
\hline Talking in the event & 4.5 & 4.3 & .87 \\
\hline The event comes to me in words & 4.2 & 4.1 & .54 \\
\hline Coherent story & 4.7 & 4.8 & -.26 \\
\hline \multicolumn{4}{|c|}{ Significance, Belief, and Rehearsal } \\
\hline Significant for my life & 4.4 & 4.3 & .46 \\
\hline Event really occurred as I remember it & 6.2 & 5.8 & 1.95 \\
\hline I have thought and talked about it & 4.3 & 4.1 & 1.46 \\
\hline Talked about it with twin & 4.6 & 4.3 & .88 \\
\hline
\end{tabular}

Note-Results of a two-tailed $t$ test $(d f=19$; random factor $=$ sets of twins $)$ are shown. $* p<.05 ; * * p<.01 ; * * * p<.001$. A similar $t$ test conducted with individuals as the random factors found the same 7 (and only 7) significant differences, although for "Actually remember the event," $p<.01$. All variables are measured on a scale from 1 to 7 , where 7 denotes more of the quality.

ever, that these account solely for the higher ratings and it also does not explain why ratings on certain of the scales, indeed scales central to theories of recollection, showed significant differences while other ratings did not.

The six open-ended questions asking each twin about the 33 disputed memories were analyzed to see whether the twins agreed, disagreed, or appeared to answer each question in different ways (for example, the twins sometimes answered the question "What were you doing immediately prior to the event?" in ways that suggested they had slightly different understandings of what "immediately" might mean in this context). This analysis was performed by two independent raters who achieved $82 \%$ agreement on their first coding and then resolved their differences by discussion.

The twins agreed about who else was present in $78 \%$ of the disputed memories and disagreed in $13 \%$. (The remaining $9 \%$ of the answers indicated a tendency to answer in different ways.) In answer to what they were doing, they agreed in $94 \%$ of the memories and disagreed in $3 \%$. They agreed about how they came to be there for $78 \%$ and disagreed for $6 \%$. They agreed about their age at the time for $81 \%$ of the memories and disagreed for $9 \%$ of them. They agreed on what they were doing immediately prior to the event for $53 \%$ of the memories and what they did immediately after the event for $56 \%$ of them. Disagreements for these two questions were $19 \%$ and $22 \%$ of the memories, respectively. Thus there was good agreement on most aspects of the memory except who the protagonist was.

Pearson correlations between the different rating scales were calculated separately for disputed and nondisputed memories, an analysis that was performed twice-once using different individuals and once using different memories as the data points. However, neither the correlations themselves nor factor analyses based on them revealed any interesting oddities regarding the disputed memories.

\section{EXPERIMENT 3}

\section{Method}

A questionnaire was distributed to 69 students during class time. The questionnaire began as follows:

\begin{abstract}
We are carrying out an experiment of disputed memories and are currently gathering data on the issue. A disputed memory is a memory in which two people agree on most of the details of what happened but disagree on to whom the event occurred. One such example of this occurred when two girls argued over which of them got sent home from school for wearing too short a skirt. They agreed on most of the details of the incident and agreed that only one of them was sent home but both believe they were the person who was actually sent home. Everyone makes mistakes in their memories, the kind of memory that we are looking for is when you get the memory mostly right except that the event never happened to you but did happen to someone else.
\end{abstract}

The questionnaire then asked the participants whether they had ever experienced this kind of memory. The participants were asked to describe any such instances and to provide details if possible about the incident, including when it occurred, who the dispute was with, and how many other such instances they could think of. They were then asked for demographic information.

\section{Results}

Of the 69 participants, 6 reported having experienced a disputed memory. Three disputed the memory with siblings and 3 with same-sex friends. Table 5 shows summary details of the reported disputed memories and provides details of each group of participants. We assumed 
Table 5

Number of Disputed Memories Reported in Experiment 3

\begin{tabular}{lccc}
\hline \multicolumn{1}{c}{$\begin{array}{c}\text { Type of Person } \\
\text { With Whom Memory } \\
\text { Was Disputed }\end{array}$} & $\begin{array}{c}\text { No. of } \\
\text { Participants }\end{array}$ & $\begin{array}{c}\text { No. of } \\
\text { Disputed } \\
\text { Memories }\end{array}$ & $\begin{array}{c}\text { Percentage of } \\
\text { Disputed } \\
\text { Memories }\end{array}$ \\
\hline Twins same-sex & $\begin{array}{c}\text { Experiment } 2 \\
\text { (2) (38 f) }\end{array}$ & 26 & 65 \\
Sibling $<2$ years same sex & Experiment 3 & & \\
Sibling $<2$ years different sex & $22(15 \mathrm{f})$ & 2 & 6 \\
Sibling $>2$ years same sex & $16(10 \mathrm{f})$ & 1 & 6 \\
Sibling $>2$ years different sex & $9(5 \mathrm{f})$ & 0 & 0 \\
Friends same sex & $14(8 \mathrm{f})$ & 0 & 4 \\
Friends different sex & $69(46 \mathrm{f})$ & 3 & 0 \\
\hline
\end{tabular}

Note-f, females.

that all of the participants had friends and thus counted the number of disputed memories between friends and siblings and whether they were the same or different gender. In order to compare these participants with twins, we also sorted them by whether they had a sibling 2 years or less apart.

Because the twins in Experiment 2 were also given a description of a disputed memory, a direct comparison between the results can be made. A test of proportion between the percentage of twins reporting disputed memories in Experiment $2(65 \%)$ and the percentage of respondents with close siblings reporting disputed memories in Experiment $3(8 \%)$ is significant at the $p<.001$ level. Thus, although other people have disputed memories, twins are significantly more likely to experience them.

\section{DISCUSSION}

The primary goal of these experiments was to establish the existence of disputed memories in twins. Anecdotal evidence had suggested that these memories existed, and our results confirm the anecdotes and indicate that disputed memories are a relatively common occurrence among twins. One of the most intriguing aspects of the studies is that despite a major shift in methodology, disputed memories of similar kinds occurred in all three studies. This suggests that disputed memories are a stable and reliable memory error, that they occur frequently among twins, and that they are open to empirical investigation with a variety of methodologies.

The change in methodology did affect the findings on gender differences. As noted earlier, in Experiment 1 we found no significant differences in the number of disputed memories male and females reported. In Experiment 2, however, we did find a significant effect for gender. This difference can in part be explained by looking at the shift in methodology and the qualitative data that emerged from Experiment 1. During the cue word experiment, $75 \%$ of the disputed memories the male twins produced were new disputes, that is, they were not aware that the memory was in dispute, and both had always assumed that the memory was their own. This may be compared with the $56 \%$ of new disputed memories that fe- male twins discovered during the cue word experiment. Given that most of the male twins' disputed memories were discovered only in the context of the cue word experiment, it is hardly surprising that only 1 in 9 males reported disputed memories in Experiment 2 (i.e., when they were asked directly whether they had experienced disputed memories with their twin, they were unaware they had any). The data from Experiment 3 support this further: No males reported having experienced a disputed memory. Possible reasons for these differences lie outside the realm of this paper, but it seems likely that because female twins talk to each other more than male twins do (Koch, 1966), they were thus more likely to discover that some of their shared memories are disputed at a higher rate than males. When, during the cue word experiment, male twins were encouraged to talk about past events together, they reported the same number of disputed memories as did female twins. In a large-scale experiment of twins, Koch showed that, in comparison with female twins, males were more withdrawn, subdued, and socially apprehensive as well as less adequate in speech and possessed of fewer interests. This could explain some of our findings on gender differences and disputed memories.

The types of autobiographical memories that were disputed by the twins do not appear, in content, to be very different from their nondisputed memories. In particular, the disputed memories in Experiment 2 had no more personal significance than did the nondisputed memories. In retrospect, this may not be surprising. It would seem unlikely, for example, that one respondent could incorrectly claim a twin's memory of being hit by a car or getting straight As in school, because independent verification would be relatively easy to find. Indeed, it is likely that twins have already resolved many of the memory disputes that can be resolved, and that those that remain, especially when, as in Experiment 2, they are already known to be disputed, are those that cannot be readily resolved.

One pair of 52-year-old twins disagreed about which of them had made a dramatic attempt at running away from home at the age of 6 . Both recalled sitting in the back of the car while the mother frantically searched the 
streets for the missing twin. There are two surprising aspects to this disputed memory. First, of all the 33 disputed memories reported in Experiment 2, this was the only one in which both twins recalled their opposite as being the protagonist in the memory as opposed to themselves. Second, an incident such as this would become part of a family's history, so it seems unusual that a critical detail such as who actually ran away could be confused. Research has shown, not surprisingly, that unique or important events from our lives are recalled better than neutral events (Wagenaar, 1986a, 1986b), although, as Linton (1982) noted in her longitudinal experiment of her own autobiographical memory, an event's salience changes over time, making the memory less accessible to recollection.

One of the most intriguing aspects of Experiment 2 was the relatively small number of disputed memories that the twins reported. Upon initial contact, many of the participants recognized the phenomenon immediately and said that they had had many arguments with their twin over disputed memories in the past, but during the actual interviews most twins could only recall one or two disputed memories. Indeed the participants often reported frustration that they could not recall further disputed memories. As one commented, "I can't believe this, I can't remember any more. We have had so many arguments over lots of memories. She is always stealing them from me and I get so mad!" Of further interest is that the disputed memories were discovered only during talking at a later date about the event that the memory concerned, whether between the twins themselves or with a third party. It appears, therefore, that disputed memories are a naturally occurring phenomenon that are discovered rather rarely and by accident, and this conclusion is supported by the number of new disputed memories discovered through the course of the cue word experiment and suggests that twins likely have many more undiscovered disputed memories. The anecdotal evidence from the participants who took part in Experiment 2 supports the view that details of disputed memories are hard to recall, in much the same way that other unusual memory incidences such as déjà vu or tip-ofthe-tongue would be.

The twins who took part were aware that one of them must have had a non-veridical recollection of the event that they remembered, but it would be hard to pick this from the qualities that were ascribed to the memories in Experiment 2 . This is particularly evident in the high ratings on the various scales that assessed the imagery present in the memory and the vividness of it, which have been defined as central to autobiographical memory (Brewer, 1986). One might also note that both disputed and nondisputed memories were usually reported from the field perspective.

The interpretation of the differences in qualia that we found between the disputed and nondisputed memories in Experiment 2 is a little unclear. Do, for example, disputed memories receive higher imagery ratings because memories that are more easily "seen in one's mind" are more likely to be disputed? Or do the disputes that the twins have had lead to more imagery, possibly as part of an attempt to assert one's ownership, possibly in part as a consequence of being asked about them by the experimenter? In theory, this issue might be resolved by first obtaining the imagery ratings and then later attempting to discover whether the memory is disputed, but the relative small number of disputed memories would make this a difficult undertaking.

In his research on the creation of false memories, Hyman (1999) suggests that three cognitive processes are involved in the process of creating false memories: Event acceptance, imagery/narrative creation, and sourcemonitoring error. He argues, first, that an event has to be deemed plausible for it to be accepted as a possible memory. Second, an image or narrative has to be formed. People often combine schematic knowledge with personal experiences and current demands to construct an image or narrative of the event; and tying the event to self-knowledge, for example, makes false memory construction more likely. Finally, a source-monitoring error must be made: A person may think an event plausible and may even be able to tell a story about the event, but that person may still not think the event an actual memory. Phenomenal characteristics of the constructed memory affect whether a source-monitoring error is made. Clearer images, and greater level of affect and selfinvolvement, for example, increase the chance that the memory will be regarded as legitimate. In the case of disputed memories in twins, it could be argued that the first two cognitive processes take place automatically, thereby making twins more susceptible to disputed memories. The event surrounding the disputed memory has occurred, and therefore event acceptance is automatic. A narrative or image has been created, either by both twins having been present and having seen the event occur or by their having heard or told the story to someone else. It is also possible that the twin with the nonveridical recollection of the event has heard someone else who confused the twins' identities (which is a common occurrence for twins; see Nairn, 1994) tell the story. Studies on behavior genetics show clear evidence that twins tend to assimilate their personalities to a far greater degree than siblings do (Plomin et al., 1990). It is possible that this assimilation of personalities and a shared combination of personal experience and schematic knowledge explain the higher frequency of disputed memories in twins than in close siblings. A further possibility is that twins are not only similar to each other but are so used to sharing things that they also share each other's memories. When they do not have their own particular memories, they use their twin's personal memories, unconsciously or otherwise, as a default.

Previous research (e.g., Brewer, 1988; Gruneberg \& Sykes, 1993) has generally found a good relationship between accuracy and confidence judgments of autobiographical memories. Laboratory experiments have also shown that belief is reliably related to accuracy (Tulving \& Thomson, 1971; Wagenaar, 1986a, 1986b). The twins 
who took part in this experiment were aware that one of them had a nonveridical memory (Greenwald, 1980; Johnson \& Raye, 1981) for the disputed event, yet neither twin was willing to concede that his or hers was the false memory. As in previous research, they were unwilling to "give up" their autobiographical memories, considering them to be true accounts of past experiences even when presented with contrary evidence (Brewer, 1986; Neisser \& Harsch, 1993).

\section{REFERENCES}

BAHRICK, H. P. (1979). Maintenance of knowledge: Questions about memory we forgot to ask. Journal of Experimental Psychology: General, 108, 296-308.

Bink, M. L., Marsh, R. L., Hicks, J. L. \& Howard, J. D. (1999). The credibility of a source influences the rate of unconscious plagiarism. Memory, 7, 293-308.

Brewer, W. F. (1986). What is autobiographical memory? In D. C. Rubin (Ed.), Autobiographical memory (pp. 25-49). Cambridge: Cambridge University Press.

BREWER, W. F. (1988). Memory for randomly sampled autobiographical events. In U. Neisser \& E. Winograd (Eds.), Remembering reconsidered: Ecological and traditional approaches to the study of memory (pp. 21-90). Cambridge: Cambridge University Press.

BREWER, W. F. (1996). What is recollective memory? In D. C. Rubin (Ed.), Remembering our past (pp. 19-66). Cambridge: Cambridge University Press.

Brewer, W. F., \& PANI, J. R. (1983). The structure of human memory. In G. H. Bower (Ed.), The psychology of learning and motivation: Advances in research and theory (Vol. 17, pp. 1-38). New York: Academic Press.

Brewer, W. F., \& Treyens, J. C. (1981). Role of schemata in memory for places. Cognitive Psychology, 13, 207-230.

Carver, C. S., \& Scheier, M. F. (2000). Perspectives on personality (4th ed.). Boston: Allyn \& Bacon.

Christianson, S. A. (1996). Emotional events and emotions in autobiographical memory. In D. C. Rubin (Ed.), Remembering our past (pp. 218-243). Cambridge: Cambridge University Press.

Crovitz, H. F., \& Schiffman, H. (1974). Frequency of episodic memories as a function of their age. Bulletin of the Psychonomic Society, 4, 517-518.

Galton, F. (1880). Statistics of mental imagery. Mind, 5, 301-318.

Greenwald, A. G. (1980). The totalitarian ego: Fabrication and revision of personal history. American Psychologist, 35, 603-618.

Gruneberg, M. M., \& Sykes, R. N. (1993). The generalisability of confidence-accuracy studies in eyewitnessing. Memory, 1, 185-189.

Hyman, I. E., JR. (1999). Creating false memories. In E. Winograd, R. Fivush, \& W. Hirst (Eds.), Ecological approaches to cognition: Essays in honor of Ulric Neisser (pp. 75-84). Mahwah, NJ: Lawrence Erlbaum.

Hy MAN, I. E., JR., \& Billings, F. J. (1998). Individual differences and the creation of false childhood memories. Memory, 6, 1-20.

Hyman, I. E. JR., \& Pentland, J. (1996). The role of mental imagery in the creation of false childhood memories. Journal of Memory \& Language, 35, 101-117

JoHnson, M. K. (1988). Reality monitoring: An experimental phenomenological approach. Journal of Experimental Psychology: General, 117, 390-394.

Johnson, M. K., \& Raye, C. L. (1981). Reality monitoring. Psychological Review, 88, 67-85.

Koch, H. L. (1966). Twins. Chicago: University of Chicago Press.

Linton, M. (1982). Transformations of memory in everyday life. In U. Neisser (Ed.), Memory observed: Remembering in natural contexts (pp. 77-91). San Francisco: W. H. Freeman.
LofTus, E. F. (1979). The malleability of human memory. American Scientist, 67, 312-320.

Loftus, E. F. (1992). When a lie becomes memory's truth: Memory distortion after exposure to misinformation. Current Directions in Psychological Science, 1, 121-123.

Loftus, E. F., \& Hoffman, H. G. (1989). Misinformation and memory: The creation of new memories. Journal of Experimental Psychology: General, 118, 100-104.

NAIRN, D. K. (1994). Emotion in twins: An exploratory experiment. Unpublished Masters thesis. New Zealand: University of Canterbury.

Neisser, U., \& Harsch, N. (1993). Phantom flashbulbs: False recollections of hearing the news about Challenger. In E. Winograd \& U. Neisser (Eds.), Affect and accuracy in recall: Studies of "flashbulb" memories (pp. 9-31). New York: Cambridge University Press.

Nigro, G., \& Neisser, U. (1983). Point of view in personal memories. Cognitive Psychology, 15, 467-482.

Pillemer, D. B. (1998). What is remembered about early childhood events. Clinical Psychology Review, 18, 895-913.

Plomin, R, DeFries, J. C., \& McClearn, G. E. (1990). Behavioral genetics: A primer (2nd ed.). New York: W. H. Freeman.

Pope, K. S. (1996). Memory, abuse, and science: Questioning claims about the false memory syndrome debate. American Psychologist, 51, 957-974.

ReISBERG, D. (Ed.) (1992). Auditory imagery. Hillsdale, NJ: Erlbaum.

Roediger, H. L., III, McDermott, K. B., \& Goff, L. M. (1997). Recovery of true and false memories: Paradoxical effects of repeated testing. In M. A. Conway (Ed.), Recovered memories and false memories: Debates in psychology (pp. 118-149). Oxford: Oxford University Press.

Ross, M., Buehler, R, \& Karr, J. W. (1998). Assessing the accuracy of conflicting autobiographical memories. Memory \& Cognition, 26, $1233-1244$

RubIN, D. C. (1982). On the retention function for autobiographical memory. Journal of Verbal Learning \& Verbal Behavior, 21, 21-38.

Rubin, D. C. (Ed.). (1996). Remembering our past. Cambridge: Cambridge University Press.

Rubin, D. C. (1998). Beginning of a theory of autobiographical remembering. In C. P. Thompson \& D. J. Herrmann (Eds.), Autobiographical memory: Theoretical and applied perspectives. Mahwah, NJ: Erlbaum.

Rubin, D. C., Scrauf, R. W., \& Greenberg, D. L. (1999). Remembering, reliving, and believing autobiographical memories: Inter- and intra-individual analyses. Unpublished manuscript.

Tulving, E. (1972). Episodic and semantic memory. In E. Tulving \& W. Donaldson (Eds.), Organization of memory (pp. 381-403). New York: Academic Press.

Tulving, E. (1983). Elements of episodic memory. New York: Oxford University Press.

Tulving, E. (1985). How many memory systems are there? American Psychologist, 40, 385-398.

Tulving, E., \& Thomson, D. M. (1971). Retrieval processes in recognition memory: Effect of associative context. Journal of Experimental Psychology, 87, 116-124.

WAGENAAR, W. A. (1986a). My memory: A study of autobiographical memory over six years. Cognitive Psychology, 18, 225-252.

WagenaAr, W. A. (1986b). People and places in my memory: A experiment on cue specificity and retrieval from autobiographical memory. In M. M. Gruneberg \& P. E. Morris (Eds.), Practical aspects of memory: Current research and issues (pp. 228-233). New York: Wiley.

Wheeler, M. A., Stuss, D. T., \& Tulving, E. (1997). Towards a theory of episodic memory: The frontal lobes and autonoetic consciousness. Psychological Bulletin, 12, 331-354.

Zaragoza, M. S., \& MCCloskey, M. (1989). Misleading postevent information and recall of the original event: Further evidence against the memory impairment hypothesis. Journal of Experimental Psychology: Learning, Memory, \& Cognition, 13, 36-44. 


\section{APPENDIX}

\section{Questionnaire From Experiment 2}

1. As I remember the event I feel as though I am reliving it [not at all to as clearly as if it was happening right now].

2. As I remember the event I can hear it in my mind not at all to as clearly as if it was happening right now].

3. As I remember the event, I can see it in my mind [not at all to as clearly as if it was happening right now].

4. As I remember the event, I or other people are talking [not at all to as clearly as if it was happening right now].

5. As I remember the event, I can feel now the emotion I felt then [not at all to as clearly as if it was happening right now].

6. As I remember the event, I can recall the setting where it occurred [not at all to as clearly as if it was happening right now].

7. Sometimes people know something happened to them without being able to actually remember it. As I think about the event I can actually remember it rather than just knowing that it happened [not at all to as much as any memory].

8. As I remember the event, it comes to me in words [not at all to as much as any memory].
9. As I remember the event, I feel that I travel back to the time when it happened, that I am a participant in it again, rather than an outside observer tied to the present [not at all to as much as any memory].

10. As I remember the event, it comes to me in words or in pictures as a coherent story or episode and not as an isolated fact, observation or scene [not at all to as much as any memory].

11. As I remember the event, I know its spatial layout [not at all to as clearly as if it was happening right now].

12. This memory is significant for my life because it imparts an important message for me or represents an anchor, critical juncture or turning point [not at all to as much as any memory].

13. I believe the event in my memory really occurred in the way I remember it and that I have not imagined or fabricated anything that did not occur [ $100 \%$ imaginary to $100 \%$ real].

14. Since it happened, I have thought or talked about this event [not at all to as often as any event in my life].

15. Since it happened, I have talked about this event with my twin [not at all to as often as any event in my life]. 